\title{
INSTRUMENTOS FINANCEIROS DE CAPITAL E DÍVIDA CONFORME O IFRS, USGAAP E BRGAAP: UM ESTUDO DE CASO DA GERDAU S.A.
}

\section{FINANCIAL INSTRUMENTS OF CAPITAL AND DEBT ACCORDING TO IFRS, USGAAP AND BRGAAP: A CASE STUDY OF THE GERDAU S.A.}

\author{
RAFAEL BORGES MORCH \\ Mestre em Ciências Contábeis pela \\ Universidade Federal do Rio de Janeiro \\ Professor Substituto do Centro de Ciências Jurídicas e \\ Econômicas da Universidade Federal do Rio de Janeiro \\ Rio de Janeiro/RJ, Brasil \\ E-mail: rafael.morch@gmail.com \\ GISELE DE SOUZA CASTRO VIEIRA \\ Mestre em Ciências Contábeis na \\ Universidade Federal do Rio de Janeiro \\ Rio de Janeiro/RJ, Brasil \\ E-mail: giscastro@yahoo.com.br.
}

\author{
MARCO AURÉLIO AMARAL \\ Mestrando em Ciências Contábeis na \\ Universidade Federal do Rio de Janeiro \\ Rio de Janeiro/RJ, Brasil \\ E-mail: marcoamaral@petrobras.com.br
}

NATAN SZUSTER

Doutor em Contabilidade pela Universidade de São Paulo Professor Doutor do Centro de Ciências Jurídicas e Econômicas da Universidade Federal do Rio de Janeiro Rio de Janeiro/RJ, Brasil

Resumo E-mail: natan.szuster@terra.com.br

O presente artigo tem por objetivo apresentar conceitos sobre títulos híbridos, ou seja, títulos com características de capital próprio, mas que, em sua essência, são obrigações. Utilizando técnicas de pesquisa bibliográfica e documental, o estudo analisa as normas contábeis internacionais, norte-americanas e brasileiras relacionadas a esse assunto, ressaltando os principais tópicos de cada uma e suas diferenças. Em seguida verifica-se como a empresa Gerdau S.A. classifica e evidencia títulos com essas características para os anos 2006, 2007 e 2008. A escolha da empresa deve-se aà divulgação de suas demonstrações contábeis em BRGAAP e USGAAP em 2006 e em IFRS e USGAAP em 2007 e 2008, permitindo assim a comparação entre as três normas. Constatou-se que, enquanto as normas internacionais e norte-americanas possuem pronunciamentos para títulos híbridos, no Brasil ainda o assunto não recebeu um tratamento específico, o que se reflete na contabilização e no grau de divulgação das informações publicadas com base nas normas brasileiras.

Palavras-chave: instrumentos financeiros; patrimônio líquido; normas contábeis.

\begin{abstract}
This paper aims to present concepts about financial instruments with characteristics of equity, but are considered liabilities. Using techniques of literature search and documentary, this study analyses the IFRS, USGAAP and BRGAAP on this issue, highlighting the main topics of each and their differences. After that it is verified as the company Gerdau S.A. classifies and evidences titles with these characteristics for the years 2006, 2007 and 2008. The choice of the company must it spreading of its countable demonstrations in BRGAAP and USGAAP in 2006 and IFRS and USGAAP in 2007 and 2008, thus allowing comparisons between the three standards. It was found that while IFRS and USGAAP have pronouncement specific, in Brazil it still received no special treatment, which is reflected in accounting and the degree of disclosure of information published on the basis of the Brazilian standards.
\end{abstract}

Key words: financial instruments, equity, accounting standards. 


\section{INTRODUÇÃO}

A contabilidade de qualquer organização ganha alcance internacional a partir do momento em que ela não se limita mais às fronteiras de sua nação, mas se estende em direção a mercados nos quais possa encontrar vantagens competitivas. 0 crescimento das companhias brasileiras com títulos emitidos na bolsa de Nova York e a avaliação de alguma delas como "investment grade" demonstra a maior confiança que investidores internacionais colocam nessas companhias quando compram seus títulos.

Logo, faz-se necessário que as empresas brasileiras apresentem corretamente suas demonstrações contábeis para não só justificar a confiança depositada por estes investidores, como também, para incentivá-los a continuar investindo em companhias nacionais. Sabe-se que casos de classificação contábil indevida ou avaliação errônea por parte das empresas, quer de forma fraudulenta ou não, acabam afetando o valor de suas ações e o nível de confiança dos acionistas em relação à companhia que, frequentemente, expande essa desconfiança para as empresas pares, sejam do mesmo ramo ou do mesmo país.

A expansão dos mercados e a globalização, aliadas à busca incessante de recursos, criaram, no mercado financeiro, inúmeras formas de captação que apresentam ao profissional contábil a difícil tarefa de, à luz do conhecimento e do arcabouço contábil existente, classificar esses instrumentos da maneira correta. Por muitas vezes, os profissionais se deparam com instrumentos financeiros complexos e surgem dúvidas em relação à classificação como passivo ou patrimônio líquido, forçando os profissionais a uma interação que não chegou ainda a um denominador comum.

Hendriksen e Breda (1999), mencionam que as constantes evoluções do mercado de capitais tem feito que novos tipos de títulos sejam criados, que muitas vezes atuam como dívidas ou participações acionárias e tem trazido complicações para o meio contábil, já que o que diferencia o patrimônio dos acionistas e das obrigações da empresa, estão ficando cada vez mais próximos.

Casson (1998) relata em seu estudo que existem duas frentes para a classificação de títulos híbridos, existem argumentos de que esses títulos devem ser apresentados, conforme suas características, entre passivo ou patrimônio, ao fato que a contabilidade deve registrar as transações conforme a substância econômica no lugar da forma legal. Um dos motivos para isso seria para fins de comparabilidade. Entretanto, o autor também relata que existem argumentos contra essa distinção devido à dificuldade em caracterizar alguns tipos de títulos como instrumento de dívida ou patrimônio.

Para os países que adotam as Normas Internacionais de Contabilidade (IFRS) o órgão de normatização International Accounting Standards Board (IASB), emitiu o IAS 32 Financial Instruments: Presentation, que estabelece princípios para a apresentação de instrumentos financeiros como passivo ou capital próprio e para a compensação entre ativos e passivos financeiros.

O motivo para a emissão do IAS 32, emitido em junho de 1995, deveu-se ao crescimento no uso de instrumentos financeiros complexos. As demonstrações financeiras dos portadores desses títulos não refletiam, adequadamente, a situação financeira deles e de seus resultados (SCHNEIDER, MCCARTHY e HAGLER, 1998).

Barth, Landsman e Rendleman (1998) demonstram em seus estudos que a classificação e a divulgação separada dos instrumentos financeiros fornecem informações que são relevantes para os usuários das demonstrações contábeis. 
Então, a proposta do IAS 32 visava à adequação da correta separação entre passivo e patrimônio liquido, como também a correta composição do resultado da empresa, adequando o que deve ser considerado como despesa financeira e o que deve ser considerado dividendos.

Bishop, Bradbury e Zijl (2005) verificaram que a adoção do IAS 32 por empresas da Nova Zelândia, fez com que houvesse uma queda em instrumentos de capital e queda nos lucros; em contrapartida houveram aumentos em instrumentos de dívidas e de despesas financeiras. Essas modificações se deram pela reclassificação de operações que antes estavam contabilizadas no Patrimônio líquido e que com o IAS 32 foram consideradas Passivos.

O órgão de normatização contábil americano, Financial Accounting Standards Board (FASB), visualizando esse intenso crescimento dos instrumentos financeiros de captação, as freqüentes dúvidas dos profissionais contábeis em relação ao tema e a falta de um entendimento único sobre o assunto resolveu divulgar o SFAS 150 - Accounting for certain financial instruments with characteristics of both liabilities and equity, emitido em 2003.

Cabe ressaltar, que o assunto ainda é novo no Brasil com quatro normas emitidas pelo Comitê de Pronunciamentos Contábeis (CPC) no ano de 2008 (CPC 14) e 2009 (CPC 38, CPC 39 e CPC 40),, o que dificulta o trabalho do contador ao identificar o tipo de instrumento financeiro e dar o tratamento adequado ao mesmo, tendo em vista tratar-se de um passivo ou capital próprio.

Desta forma, o presente trabalho objetiva comparar os pontos mais divergentes na forma de contabilização de títulos híbridos entre as normas internacionais, norteamericanas e brasileiras. Para alcançar este objetivo pretende-se identificar possíveis diferenças na aplicabilidade das técnicas e conceitos apresentados na literatura norteamericana (SFAS 150) e internacional (IAS 32) sobre a classificação dos instrumentos híbridos de capital e dívida e sua aplicação no Brasil, atentando para as divergências entre os dois cenários e propondo melhorias sempre que se verificar uma lacuna importante no arcabouço contábil brasileiro.

Para isso, o artigo parte do atual pronunciamento do IASB (IAS 32) que trata da apresentação dos instrumentos financeiros de capital e dívida e busca similaridades e diferenças nos pronunciamentos emitidos pelo FASB (SFAS 150) e pelo Brasil a respeito do assunto. A escolha do IAS 32 como referência deve-se ao fato do IASB ser visto como o "condutor" do processo de harmonização contábil, responsável pela elaboração dos padrões contábeis internacionais.

Os seguintes passos metodológicos serão seguidos no presente estudo: (a) relacionar as normas básicas anteriores do arcabouço contábil brasileiro tratando da classificação de títulos como passivo ou como patrimônio líquido, visto que não existe norma específica para o assunto no país; (b) identificar os conceitos apresentados pela norma internacional (IAS 32) e a norte-americana (SFAS 150) e comparar com procedimentos ou normas em separado no Brasil que abordem o assunto para explicitar diferenças; (c) evidenciar que tipos de instrumentos financeiros utilizados no Brasil seriam suscetíveis à aplicação da norma norte-americana; (d) analisar como a Gerdau S.A., que reporta suas demonstrações financeiras à Securities and Exchange Comission (SEC), classifica seus títulos híbridos em suas divulgações obrigatórias; e (e) verificar o tratamento dado às demonstrações contábeis brasileiras, apresentadas à Comissão de Valores Mobiliários (CVM), com base em normas brasileiras (BRGAAP) e em IFRS, no que tange aos mesmos instrumentos classificados nas demonstrações utilizando as normas norte-americanas (USGAAP) para verificação da consistência entre os critérios adotados.

Esta pesquisa se classifica, segundo a tipologia proposta por Raupp e Beuren (2003) quanto aos objetivos como exploratória; quanto aos procedimentos ela é, 
simultaneamente, pesquisa, documental e estudo de caso; e, quanto à abordagem do problema, ela é qualitativa. A pesquisa documental está centrada na literatura americana sobre o tratamento dado aos títulos híbridos de capital e dívida (SFAS 150), na norma internacional sobre apresentação dos instrumentos financeiros (IAS 32) e na recente norma brasileira que trata de instrumentos financeiros: reconhecimento, mensuração e evidenciação (CPC 14). A pesquisa documental será utilizada ainda na comparação entre as normas, através do exame dos relatórios contábeis emitidos pela empresa utilizada no presente estudo em USGAAP e BRGAAP no ano de 2006, e em USGAAP e IFRS (em substituição ao BRGAAP, de acordo com opcionalidade dada pela CVM através da instrução 457, de 13 de julho de 2007) no ano de 2007 e 2008.

Trata-se de estudo de caso, pois se caracteriza como um tipo de pesquisa cujo objeto central de análise é o exame detalhado de um determinado fenômeno que é investigado em profundidade (GODOY, 2007) A escolha da Gerdau S.A. para exemplificar e comparar a aplicação das referidas normas se deve ao fato da empresa possuir títulos que se caracterizam como híbridos, além de ter, já no último exercício encerrado, publicado suas demonstrações contábeis conforme as normas IFRS, de acordo com autorização dada pela referida Instrução 457 da CVM. A companhia também publica em USGAAP uma vez que possui títulos na Bolsa de Nova York.

\section{CONTABILIZAÇÃO DE TÍTULOS HÍBRIDOS}

\subsection{NORMAS INTERNACIONAIS - IFRS}

De acordo com o IAS 32 - Financial Instruments: Presentation, "um instrumento financeiro é qualquer contrato que dê origem a um ativo financeiro de uma entidade e a um passivo financeiro ou instrumento de capital próprio de uma outra entidade" (IAS 32, parágrafo 11). seja:

No IAS 32, parágrafo 11, encontra-se a definição do termo ativo financeiro, qual Um ativo financeiro é qualquer ativo que seja:

(a) dinheiro;

(b) um instrumento de capital próprio de uma outra entidade;

(c) um direito contratual:

(i) de receber dinheiro ou outro ativo financeiro de outra entidade; ou

(ii) de trocar ativos financeiros ou passivos financeiros com outra entidade em condições que sejam potencialmente favoráveis para a entidade; ou

(d) um contrato que será ou poderá ser liquidado nos instrumentos de capital próprio da própria entidade e que seja:

(i) um não derivativo para o qual a entidade esteja ou possa estar obrigada a receber um número variável dos instrumentos de capital próprio da própria entidade; ou

(ii) um derivativo que será ou poderá ser liquidado de forma diferente da troca de uma quantia fixa em dinheiro ou outro ativo financeiro por um número fixo dos instrumentos de capital próprio da própria entidade. Para esta finalidade, os instrumentos de capital próprio da própria entidade não incluem instrumentos que sejam eles próprios 
contratos para futuro recebimento ou entrega dos instrumentos de capital próprio da própria entidade.

Exemplos comuns de ativos financeiros são o numerário em caixa, os depósitos bancários, as contas a receber, empréstimos a receber, ativos físicos e intangíveis. Outros instrumentos financeiros, como as debêntures, também são ativos financeiros, pois proporcionam normalmente ao detentor o direito contratual de receber pagamentos por conta de juros em datas fixas que se prolongam por um futuro indefinido, seja sem qualquer direito de receber um retorno de capital, seja um direito a um retorno de capital segundo termos que tornem isso muito improvável ou muito longínquo no futuro.

Já o termo passivo financeiro, foi conceituado pelo IAS 32 da seguinte forma:

Um passivo financeiro é qualquer passivo que seja:

(a) uma obrigação contratual:

(i) de entregar dinheiro ou outro ativo financeiro a uma outra entidade; ou

(ii) de trocar ativos financeiros ou passivos financeiros com outra entidade em condições que sejam potencialmente desfavoráveis para a entidade; ou

(b) um contrato que será ou poderá ser liquidado nos instrumentos de capital próprio da própria entidade e que seja:

(i) um não derivativo para o qual a entidade esteja ou possa estar obrigada a entregar um número variável de instrumentos de capital próprio da própria entidade; ou

(ii) um derivativo que será ou poderá ser liquidado de forma diferente da troca de uma quantia fixa em dinheiro ou outro ativo financeiro por um número fixo dos instrumentos de capital próprio da própria entidade. Para esta finalidade, os instrumentos de capital próprio da própria entidade não incluem instrumentos que sejam eles próprios contratos para futuro recebimento ou entrega dos instrumentos de capital próprio da própria entidade. (IAS 32, idem).

Por fim, a conceituação proposta pela referida norma para os instrumentos de capital próprio estabelece que "Um instrumento de capital próprio é qualquer contrato que evidencie um interesse residual nos ativos de uma entidade após dedução de todos os seus passivos" (IAS 32, ibidem).

Alguns exemplos de instrumentos de capital próprio são as ações ordinárias sem opção put, alguns tipos de ações preferenciais e warrants ou opções call emitidas que permitam ao detentor subscrever ou comprar um número fixo de ações ordinárias na entidade emissora em troca de uma quantia fixa em dinheiro ou de outro ativo financeiro.

A classificação de um instrumento financeiro como capital próprio ou passivo financeiro deve levar em consideração as condições apresentadas no parágrafo 16 do IAS 32. Segundo o mesmo, o instrumento é de capital próprio se, e apenas se, as seguintes condições forem cumpridas:

(a) $O$ instrumento não inclui qualquer obrigação contratual:

(i) de entregar dinheiro ou outro ativo financeiro a uma outra entidade; ou

(ii) de trocar ativos financeiros ou passivos financeiros com outra entidade em condições que sejam potencialmente desfavoráveis para o emitente. 
(b) Se o instrumento for ou poderá ser liquidado nos instrumentos de capital próprio do próprio emitente, é:

(i) um não derivativo que não inclui qualquer obrigação contratual para o emitente de entregar um número variável dos seus próprios instrumentos de capital próprio; ou

(ii) um derivativo que será liquidado apenas pelo emitente trocando uma quantia fixa em dinheiro ou outro ativo financeiro por um número fixo dos seus próprios instrumentos de capital próprio. Para esta finalidade, os instrumentos de capital próprio do próprio emitente não incluem instrumentos que sejam eles próprios contratos para o futuro recebimento ou entrega dos instrumentos de capital próprio do próprio emitente.

Cabe destacar o exposto no parágrafo 18 da IAS 32, o qual ressalta que a essência do instrumento financeiro, mais do que sua forma legal, é que regirá sua classificação no balanço da entidade. Isso porque, alguns instrumentos tomam a forma legal de capital próprio embora sejam passivos em essência e outros podem combinar características de um e outro. Dois exemplos são utilizados pela norma para exemplificar a prevalência da essência sobre a forma, quais sejam: (a) uma ação preferencial que esteja sujeita ao resgate obrigatório pelo emitente por uma quantia fixa ou determinável numa data futura fixa ou determinável ou der ao detentor o direito de exigir que o emitente resgate o instrumento em ou após uma data particular por uma quantia fixa ou determinável, é um passivo financeiro; (b) um instrumento financeiro que dá ao detentor o direito de entregar de volta o instrumento ao emitente em troca de dinheiro ou outro ativo financeiro (instrumento com opção put) é também um passivo financeiro.

Ao determinar se uma ação preferencial é um passivo financeiro ou um instrumento de capital próprio, a norma esclarece que o emitente deve avaliar os direitos específicos associados à ação para determinar se ela exibe ou não característica fundamental de um passivo financeiro. Por exemplo, uma ação preferencial que proporcione resgate numa data específica ou de acordo com a opção do detentor contém um passivo financeiro porque o emitente tem a obrigação de transferir ativos financeiros para o detentor da ação. Por outro lado, uma opção do emitente de resgatar as ações por dinheiro não satisfaz a definição de passivo financeiro porque o emitente não tem uma obrigação presente de transferir ativos financeiros para os acionistas.

A norma torna claro, ainda, que, no caso de ações preferenciais não resgatáveis, a classificação apropriada será determinada pelos outros direitos que a elas estejam ligados. Ou seja, leva-se em consideração a essência dos acordos contratuais e das definições de passivo financeiro e instrumento de capital próprio. Dessa forma, caso prevaleça a vontade do emitente de efetuar distribuições aos detentores das ações preferenciais, as mesmas serão classificadas como instrumentos de capital próprio.

\subsection{NORMAS NORTE-AMERICANAS - USGAAP}

O FASB publicou vários pronunciamentos a respeito de instrumentos financeiros. Um deles é o SFAS $n^{\circ} 105$, que trata da divulgação das informações sobre instrumentos financeiros com risco fora do balanço geral, e instrumentos financeiros com concentração de risco de credito. O SFAS $n^{\circ} 107$, por sua vez, define o que deve constar no corpo das demonstrações ou em notas explicativas, o valor justo dos instrumentos financeiros, evidenciando os métodos usados para estimar o valor justo. Tem-se ainda, o SFAS $\mathrm{n}^{\circ} 119$, onde diz que devem ser evidenciados os derivativos com características similares, distinguindo pelo propósito de negociação, apresentado o valor de mercado e os riscos assumidos. Além disso, existe o SFAS 133, emitido em 1998, que é uma proposta para contabilização dos derivativos. 
A norma SFAS 150 é a norma norte-americana que se propõe a definir como um emissor irá classificar e quantificar instrumentos financeiros com características tanto de passivo como de capital próprio. O SFAS 150 requer que os instrumentos previstos em seu escopo sejam tratados como passivo, pois muitos destes instrumentos, antes da sua emissão, eram classificados como capital próprio. Algumas das proposições estão em linha com a definição presente no FASB Concepts statement $N^{\circ} 6$ e outras são consistentes com a proposta do FASB de revisar a definição para contemplar certas obrigações que a empresa pode ou precisa liquidar através da emissão de ações próprias, dependendo da natureza da relação estabelecida entre o detentor do instrumento e o emissor deste.

0 escopo da referida norma requer que o emissor de um instrumento financeiro classifique os seguintes instrumentos como passivos (ou ativos em certas circunstâncias):

- Mandatorily Redeemable Financial Instruments - um instrumento financeiro emitido na forma de ações e obrigatoriamente recomprável - que possua uma obrigação incondicional do emissor de recomprá-lo pela transferência de seus ativos numa data específica ou determinada ou ainda quando da ocorrência de um evento certo;

* Obligations to repurchase an issuer's equity shares that require a transfer of assets: um instrumento financeiro, diferente de uma ação negociável, que na data de sua emissão, possua uma obrigação de recompra das ações do emissor ou que esteja indexada a estas e que requeira ou possa requerer ao emissor liquidar a obrigação pela transferência de ativos (por exemplo, um contrato futuro de compra ou o lançamento de uma opção de venda de ações do emissor que precisem ser fisicamente liquidadas ou liquidadas financeiramente pela diferença entre preços);

* Certain Obligations to issue a variable number of shares: um instrumento financeiro que preveja uma obrigação incondicional, ou um instrumento financeiro diferente de uma ação negociável que preveja uma obrigação condicional em que o emissor precise ou possa liquidá-lo com uma quantidade variável de ações, se na sua emissão, o valor monetário da obrigação é baseado somente ou predominantemente em algum dos seguintes:

a. Uma quantia monetária fixa na emissão, por exemplo, uma obrigação liquidável com um número variável de ações do emissor;

b. Variação de algo diferente do valor justo das ações do emissor, por exemplo, um instrumento financeiro indexado ao IBOVESPA e liquidável com um número variável de ações do emissor;

c. Variação inversamente relacionada a mudanças no valor justo das ações do emissor, por exemplo, o lançamento de uma opção de venda que poderia ser liquidado pela diferença entre valores através da entrega de ações.

Esse pronunciamento veio sanar dúvidas de companhias que criaram instrumentos financeiros com compromissos de recompras ou obrigações de honrar instrumentos financeiros ou liquidações outras com a emissão de quantidades variáveis de ações. As formas de liquidação previstas são três, aplicáveis da seguinte forma:

Physical settlement: liquidação por meio da entrega de ações do emissor para resgate do instrumento financeiro;

Net cash settlement: liquidação por meio da entrega de numerário referente ao valor de ajuste do instrumento financeiro;

Net share settlement: liquidação por meio de uma quantidade variável de ações do emissor referente ao valor de ajuste do instrumento financeiro. 
Estes instrumentos eram contabilizados pelas companhias totalmente como capital próprio ou parcialmente como capital e o restante como passivo. 0 pronunciamento veio confirmar que todos os instrumentos que possuem a obrigação de recompra (condicionada ou não a um evento futuro), mesmo que liquidados com a emissão de ações do emissor, devem ser classificados como passivos.

Ao contrário, para ser considerado capital próprio, uma companhia que emite ações geralmente não incorre na obrigação de recomprar as ações seja através da transferência de ativos ou da emissão de ações adicionais.

\subsection{NORMAS BRASILEIRAS - BRGAAP}

No dia 27 de dezembro de 2007 foi aprovada a Lei 11.638 que altera alguns dispositivos da Lei 6.404/76. Com a nova Lei, as normas expedidas pela Comissão de Valores Mobiliários e os Pronunciamentos Contábeis, as demonstrações deverão ser elaboradas em consonância com os padrões internacionais de contabilidade adotados nos principais mercados de valores mobiliários. Isso significa que a normatização contábil para a elaboração das demonstrações financeiras individuais está convergindo, gradativamente, para as normas internacionais. Este programa de convergência vem sendo coordenado pelo Comitê de Pronunciamentos Contábeis (CPC). Espera-se, neste sentido, que o tema abordado no presente estudo venha a ser aprofundado pelo CPC, procurando suprir algumas lacunas existentes hoje no Brasil e, através de normas que tratem da classificação clara e adequada aos títulos de natureza híbrida.

Atualmente no Brasil, existe o Pronunciamento Técnico CPC 14, que foi emitido em 05 de dezembro de 2008, que aborda o reconhecimento, mensuração e evidenciação de instrumentos financeiros.

Anteriormente, a principal norma que dispunha sobre a divulgação, em nota explicativa, do valor de mercado dos instrumentos financeiros, reconhecidos ou não nas demonstrações financeiras das companhias abertas era a Instrução Normativa 235 da CVM publicada em 23 de março de 1995.

Segundo o CPC 14, que foi aprovado pela CVM e editado através da Deliberação $N^{\circ}$ 566, instrumento financeiro é definido como: "qualquer contrato que dá origem a um ativo financeiro em uma entidade e a um passivo financeiro ou título representativo do patrimônio em outra entidade".

Segundo o CPC 14, são considerados como ativos financeiros:

a) caixa;

b) direitos contratuais recebíveis em moeda ou em ativo financeiro de outra entidade;

c) direitos contratuais de troca de resultados financeiros ou instrumentos financeiros com outra entidade; e

d) títulos representativos de participação no patrimônio de outra entidade.

Ainda no mesmo, em seu parágrafo $6^{\circ}$, são caracterizados como passivos financeiros as obrigações contratuais de:
a) pagamento de determinada importância em moeda ou em ativo financeiro;
b) troca de resultados financeiros ou instrumentos financeiros; e
c) títulos representativos de participação no patrimônio de outra entidade. 
0 modelo emitido pelo CPC pode ser igualado às normas internacionais e norteamericanas. Propões que todos os instrumentos financeiros sejam classificados em 4 grandes grupos: empréstimos e recebíveis, investimentos mantidos até o vencimento, instrumentos financeiros mensurado ao valor justo por meio do Resultado, e ativos financeiros disponíveis para venda. Antes do período de convergência, a Instrução CVM 235/95 mostrava-se insuficiente por não apresentar a maneira adequada para divulgação e nem mesmo de identificava os instrumentos financeiros.

Entretanto, com relação às debêntures, o Pronunciamento não especifica a forma exata de seu reconhecimento. $O$ art. 55 da Lei 6.404/76 que trata do vencimento, amortização e resgate de debêntures, em seu parágrafo $3^{\circ}$, afirma que: "A companhia poderá emitir debêntures cujo vencimento somente ocorra nos casos de inadimplemento da obrigação de pagar juros e dissolução da companhia, ou de outras condições previstas no título". Ou seja, existe a possibilidade de as empresas emitirem tanto debêntures com vencimento indefinido quanto outros títulos de dívida com vencimento indeterminado. Esses títulos são chamados de títulos perpétuos e possuem características especiais para sua contabilização.

A maior dúvida surge com relação ao reconhecimento deste tipo de instrumento financeiro, como passivo ou patrimônio líquido. Segundo a FIPECAFI (2007), esses títulos são, via de regra, itens do passivo exigível de longo prazo. Todavia, alguns títulos podem ter embutidas cláusulas que façam com que suas características sejam híbridas, mais próximas de um título patrimonial do que de um passivo.

Ainda não há nenhuma norma que especifique o reconhecimento exato dos títulos financeiros. Dessa forma, a FIPECAFI (2007) recomenda uma análise minuciosa da essência econômica da transação, sendo importante que se conheça adequadamente as cláusulas contratuais do título em análise. No caso de um título perpétuo em que não há a possibilidade de recompra pela empresa e em que há a possibilidade de conversão para ações da empresa por seus detentores, o título se tornaria mais próximo de um item patrimonial do que de um passivo.

Todavia, a Lei 6.404/76 não prevê este tipo de instrumento e, portanto, não deixa espaço para sua classificação como item do patrimônio líquido. Para que isso seja possível, a FIPECAFI (2007) recomenda que se deva recorrer a uma autorização prévia de órgãos reguladores como a CVM e o Banco Central. Atente-se, porém, que quando houver cláusulas de resgate antecipado e a intenção da empresa em resgatar seu título perpétuo, o mesmo deve ser reclassificado para o passivo circulante no exercício anterior ao vencimento da cláusula.

\section{COMPARAÇÃO ENTRE AS NORMAS CONTÁBEIS - O CASO DA GERDAU} S.A.

A comparação simples das duas normas contábeis mais densas sobre o assunto, a internacional e a norte-americana, não apresenta grandes diferenças. O IAS 32 prevê que:

Uma característica crítica na diferenciação entre um passivo financeiro e um instrumento de capital próprio é a existência de uma obrigação contratual de um participante no instrumento financeiro (o emitente) seja de entregar dinheiro ou outro ativo financeiro ao outro participante (o detentor) seja de trocar ativos financeiros ou passivos financeiros com 0 detentor. Em condições que sejam potencialmente desfavoráveis para o emitente. (IAS 32, parágrafo 17) 
Esta diferenciação também é prevista pelas normas norte-americanas (SFAS 150) quando esta prevê que a essência deve prevalecer sobre a forma. Ou seja, se existe uma obrigação por parte do emissor do instrumento e mesmo que essa obrigação seja liquidável em ações do emissor o valor justo deste instrumento deveria ser registrado no passivo e não como capital próprio. Já nas normas brasileiras relacionadas ao assunto (CPC 14), somente é citada a classificação de ganhos ou perdas de ativos financeiros em patrimônio líquido, e não há a devida diferenciação entre o que seria passivo financeiro e instrumento de capital próprio.

\subsection{O CASO DA GERDAU S.A.}

O Grupo Gerdau é uma organização empresarial focada em siderurgia, com sede na cidade de Porto Alegre e, no último ano, obteve um faturamento bruto de $\mathrm{R} \$ 46,7$ bilhões, tendo um lucro de $\mathrm{R} \$ 4,9$ bilhões.

A operação sob a qual se baseará esta análise refere-se a uma opção de venda do grupo Santander de 40\% na participação da empresa Corporación Sidenor S.A.

Analisando as demonstrações elaboradas com base nas normas brasileiras efetuadas para o exercício findo em 2006, ou seja, antes da Lei 11.638 e da Instrução CVM 457, a Gerdau S.A. não reconhece nenhuma obrigação pela opção de 40\% da Corporación Sidenor S.A. junto ao Santander.

Essa operação está mencionada na nota explicativa 4, letra c, item I:

Em 10/01/2006, o Grupo Gerdau concluiu, em conjunto com duas empresas espanholas, a aquisição da totalidade das ações da Corporación Sidenor, S.A. (Sidenor), localizada na Espanha, cujo contrato de compra e venda fora assinado em 15/11/2005.

A participação no capital social da Corporación Sidenor, S.A. é $40 \%$ pertencente à Gerdau Hungria Holdings Limited Liability Company, $40 \%$ à Carpe Diem Salud S.L., (Carpe Diem), empresa do Grupo Santander, e 20\% à Bogey Holding Company Spain, S.L., holding dos executivos da Sidenor.

[...] A Carpe Diem detém o direito de vender sua participação na Sidenor para o Grupo Gerdau após um período de 5 anos (opção de venda), por um preço fixo atualizado. Quando e se a Carpe Diem exercer essa opção, a Gerdau ainda terá direito, se assim the convier, a indicar um terceiro para adquirir essa participação. As Demonstrações Contábeis da Corporación Sidenor, S.A. e empresas controladas foram incluídas no consolidado do Grupo Gerdau através de consolidação proporcional, a partir do primeiro trimestre de 2006.

Por sua vez, ao analisarmos os demonstrativos publicados em USGAAP para o mesmo exercício, pode-se observar que o mesmo foi considerado um instrumento de capital próprio, sendo contabilizado em participação de acionistas minoritários. A classificação deste instrumento financeiro no Balanço Patrimonial Consolidado em USGAAP pode ser vista no trecho transcrito a seguir: 
Passivo exigivel a longo prazo

Financiamentos de longo prazo, líquido da parcela circulante

Debêntures

Imposto de renda diferido

Obrigações com plano de pensão e outros beneficios pós-emprego

Provisão para contingências

Perdas não realizadas com derivativos

Créditos diferidos relacionados a aquisição da Corporação Sidenor

Outras contas a pagar

$$
\text { Total do exigivel a longo prazo }
$$

Total do passivo

Compromissos e contingências

Participação dos minoritários

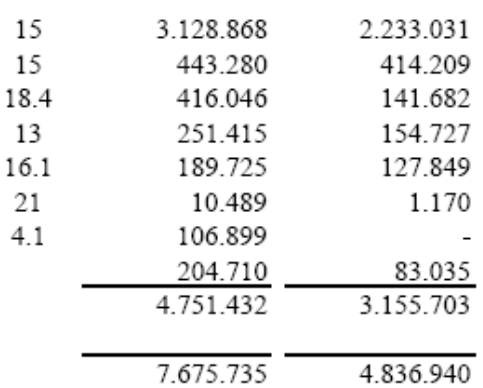

16

1.882 .489

Figura 1 - Contabilização da opção de participação na Sidenor - USGAAP em 2006 Fonte: Balanço Patrimonial Consolidado Gerdau S.A. 2006 - USGAAP

A operação registrada como instrumento de capital próprio foi exaustivamente explicada através da nota explicativa 4.1. Segue abaixo alguns trechos da referida nota:

o Grupo Santander possui uma opção de vender a sua participação na Sidenor para a Companhia após 5 anos da compra, a um preço fixo com juros computados utilizando uma taxa fixa de juros. Ainda, a Companhia acordou em garantir ao Grupo Santander o pagamento de um montante acordado (igual ao preço fixo da opção de venda mencionada acima e juros incorridos utilizando a mesma taxa fixa de juros) depois de 6 anos da compra, no caso do Grupo Santander não tiver vendido as ações adquiridas até esta data, ou, se o Grupo Santander vender sua participação a um preço maior ou menor do que o montante acordado, a diferença será paga pelo Grupo Santander à Companhia ou será paga pela Companhia ao Grupo Santander, respectivamente. A garantia pode ser exercida a qualquer tempo pelo Grupo Santander depois de 6 anos.

\section{[...]}

A obrigação da Companhia de comprar do Grupo Santander a participação de $40 \%$ na Corporación Sidenor foi registrada como Participação dos acionistas minoritários. Em 31 de dezembro de 2006, esta obrigação totaliza \$246.005.

Analisando a nota explicativa em BRGAAP supracitada, em comparação às informações publicadas no relatório elaborado conforme as normas norte-americanas no mesmo ano, verifica-se que aquela está muito aquém desta. Cabe ressaltar que não há publicação das demonstrações contábeis anuais da Empresa, para este mesmo ano, de acordo com as normas internacionais.

Conforme visto, o Brasil ainda está se adequando às normas internacionais, mas falta uma normatização mais pragmática. As informações divulgadas eram mais sucintas e, por muitas vezes, deixavam margem para interpretações errôneas. Além disso, podia ocasionar ainda o afastamento de possíveis investidores que não conseguiam fazer projeções adequadas para seus investimentos. Com as novas normas as informações estão similares no ano de 2008 às normas internacionais, entretanto, ainda há brechas com relação à classificação de algumas contas.

Quando se compara as demonstrações em BRGAAP e USGAAP com as demonstrações contábeis anuais consolidadas da Gerdau S.A. apresentadas de acordo com as normas internacionais (IFRS) nos períodos findos em 2007 e em 2008 (opcionalidade dada pela CVM por meio da instrução 457, de 13 de julho de 2007), verifica-se que esse instrumento foi classificado como uma obrigação, por entender que no caso do Grupo Santander exercer o 
direito de venda de 40\% das ações da Corporacion Sidenor para a Gerdau S.A. esta obrigada a pagar o valor contratado que é uma parcela fixa adicionada aos juros do período.

Segue trecho do Balanço Patrimonial em IFRS no ano de 2006 a 2008, mostrando a contabilização do instrumento financeiro como obrigação de longo prazo:

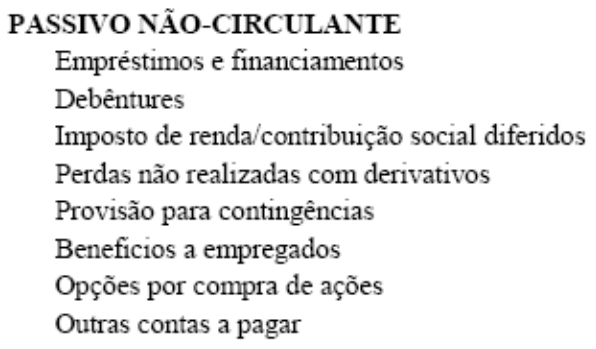

\begin{tabular}{rrrr} 
& \multicolumn{1}{c}{$\mathbf{2 0 0 8}$} & \multicolumn{1}{c}{$\mathbf{2 0 0 7}$} & \multicolumn{1}{c}{$\mathbf{2 0 0 6}$} \\
14 & 18.595 .002 & 12.461 .128 & 6.671 .456 \\
15 & 705.715 & 903.151 & 929.024 \\
9 & 3.060 .268 & 2.315 .771 & 1.474 .931 \\
16 & 314.267 & 16.106 & 22.425 \\
18 & 467.076 & 489.103 & 402.795 \\
20 & 1.275 .985 & 794.125 & 708.316 \\
$16-f$ & 698.321 & 889.440 & 547.953 \\
& 414.865 & 379.589 & 459.720 \\
\cline { 2 - 3 } & 25.531 .499 & 18.248 .413 & 11.216 .620
\end{tabular}

Figura 2 - Contabilização da opção de participação na Sidenor - IFRS em 2008. Fonte: Balanço Patrimonial Consolidado Gerdau S.A. 2008 e 2007 - IFRS

No parágrafo seguinte, está apresentada a nota explicativa 16-f onde a companhia informa que o valor justo do instrumento financeiro foi classificado como um passivo não circulante na conta Opções por compra de ações; em contra-partida, a Gerdau S.A. reconheceu $80 \%$ da Sidenor como seu investimento.

Em 10/01/2006, a Companhia concluiu a aquisição de 40\% da Corporación Sidenor S.A. ("Sidenor"), uma produtora de aços espanhola com operações na Espanha e no Brasil. O Grupo Santander, conglomerado financeiro espanhol, comprou $40 \%$ da Sidenor. O preço de aquisição de $100 \%$ da Sidenor consiste de uma parcela fixa de $€ 443.820$ mil mais uma parcela variável contingente, a ser paga apenas pela Companhia. 0 preço fixo pago pela Companhia em 10/01/2006 por sua participação de $40 \%$ na Sidenor foi de $€ 165.828$ mil (R\$ 432.577). O Grupo Santander possui uma opção de vender a sua participação na Sidenor para a Companhia após 5 anos da compra, a um preço fixo com juros calculados utilizando uma taxa fixa de juros, tendo a Sidenor o direito de preferência de adquirir estas ações, podendo ainda, a qualquer momento durante o prazo de vigência da opção de venda, requerer que o Grupo Santander exerça esta opção de forma antecipada. Ademais, a Companhia consentiu em garantir ao Grupo Santander um montante acordado (igual ao preço fixo da opção de venda mencionada acima mais juros incorridos utilizando a mesma taxa fixa de juros), a qualquer momento, por 6 anos após o exercício da opção, caso o Grupo Santander não tenha vendido as ações até essa data. Neste caso, se requerido pelo Grupo Santander o pagamento da garantia, a Companhia passa a ter o direito de adquirir as ações da Sidenor ou indicar um terceiro para a aquisição e o valor recebido pela venda das ações e dividendos pagos pela Sidenor ao Grupo Santander deverão ser reembolsados à Companhia. A obrigação potencial da Companhia de comprar do Grupo Santander a participação de $40 \%$ na Sidenor foi registrada como um passivo não-circulante na conta "Obrigações por compra de ações". Como resultado do reconhecimento desta obrigação potencial, a Companhia reconhece desde a data de aquisição $80 \%$ da Sidenor como seu investimento. Em 31/12/2008, esta obrigação potencial totaliza R\$ 553.296 (R\$ 471.477 em 31/12/2007 e R\$ 547.953 em 31/12/2006).

$\mathrm{Na}$ sequência deste mesmo parágrafo menciona-se outra operação com as características semelhantes, mas desta vez envolvendo a Gerdau Aços Villares e a BNDESPAR: 
[...] Durante o exercício de 2007, a subsidiária Gerdau Aços Especiais S.A. celebrou um contrato com o BNDES Participações S.A. ("BNDESPAR"), o maior acionista não-controlador da controlada indireta (em conjunto com terceiros) Aços Villares S.A. ("Villares"). Este contrato concedia à BNDESPAR a opção de vender para a Companhia sua participação de $28,8 \%$ na Villares, por um preço determinado. Em 31/12/2007, o valor de mercado desta opção de venda era zero em decorrência do valor das ações detidas pelo banco ser superior ao valor da opção. Conforme estabelecido pela norma IAS 32 (Apresentação dos instrumentos financeiros), a Companhia efetuou a reclassificação do valor de exercício da put option (opção de venda) da conta "Participações dos acionistas não-controladores" para o passivo não-circulante, na conta "Obrigações por compra de ações". Em 31/12/2007 o valor reconhecido como obrigação potencial totalizava $\mathrm{R} \$$ 417.963. Em virtude do BNDESPAR ter vendido suas ações para a Metalúrgica Gerdau S.A., a opção deixa de existir e a reclassificação da conta "Participações dos acionistas nãocontroladores" para a conta "Obrigações por compra de ações" no passivo não-circulante foi revertida para o exercício findo em 31/12/2008.

Conforme explicação desta parte do parágrafo, mesmo a operação não ser passível de realização, devido ao valor das ações serem superiores ao valor da opção, o IAS 32 estabelece o reconhecimento desse instrumento como uma obrigação.

Nas demonstrações contábeis preparadas de acordo com o USGAAP para o exercício findo em 2007 (até a data de fechamento desta pesquisa não havia sido divulgado o relatório em USGAAP de 2008), a companhia mantém a mesma classificação já mostrada para o exercício de 2006, ou seja, reconhece o instrumento financeiro como instrumento de capital próprio:

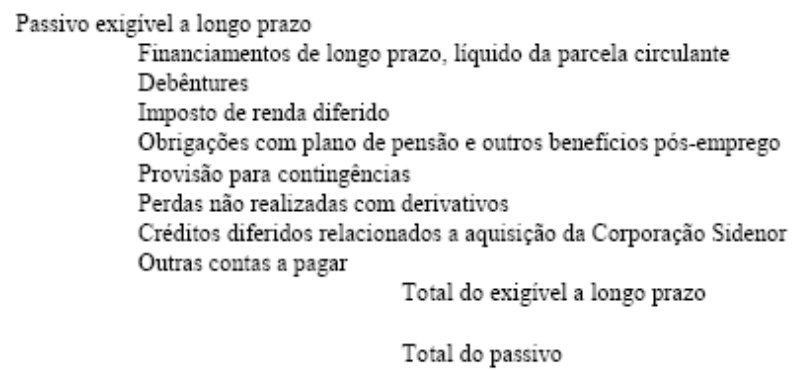

Compromissos e contingências

Participação dos minoritários

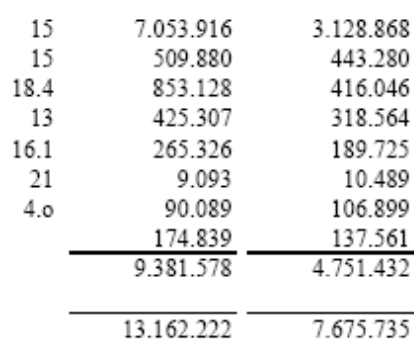

16

Figura 3 - Contabilização da opção de participação na Sidenor - USGAAP em 2007. Fonte: Balanço Patrimonial Consolidado Gerdau S.A. 2007 - USGAAP

Transcreve-se, a seguir, parte da nota que trata do assunto com a indicação de na qual foi classificado o valor do instrumento financeiro:

[...] O Grupo Santander possui uma opção de vender a sua participação na Sidenor para a Companhia após 5 anos da compra, a um preço fixo com juros computados utilizando uma taxa fixa de juros. O Santander possui o direito de vender a terceiros no caso de não haver sucesso no exercício desta opção e se o Grupo Santander vender sua participação a um preço maior ou menor do que o montante acordado, a diferença será paga pelo Grupo Santander à Companhia ou será paga pela Companhia ao Grupo Santander, respectivamente. A garantia pode ser exercida a qualquer tempo pelo Grupo Santander depois de 6 anos. Ainda, a Companhia acordou em garantir ao Grupo Santander o pagamento de um montante acordado (igual ao preço fixo da opção de venda mencionada acima e 
juros incorridos utilizando a mesma taxa fixa de juros) depois de 6 anos da compra, no caso do Grupo Santander não tiver vendido as ações adquiridas até esta data. A qualquer momento durante o prazo de vigência da opção de venda, a Sidenor tem o direito de requerer, mediante solicitação formal, que o Santander exerça esta opção de forma antecipada.

[...] A obrigação da Companhia de comprar do Grupo Santander a participação de 40\% na Corporación Sidenor foi registrada como Participação dos acionistas minoritários. Em 31 de dezembro de 2007, esta obrigação totaliza \$266.176.

O relatório do terceiro trimestre de 2008 mantém a mesma classificação do relatório do exercício findo em 2007.

Como verificado, através da análise das demonstrações da Gerdau S.A., a divulgação pelas normas norte-americanas diverge das informações divulgadas pelas normas internacionais para a mesma operação.

No exercício findo em 31/12/2008 a Gerdau arquivou na SEC seu relatório com base no IFRS, e não mais em USGAAP. A SEC permite isto desde que haja uma reconciliação do Patrimônio Líquido e do Lucro Líquido das diferenças entre IFRS e USGAAP.

Na nota explicativa 31 a Gerdau fez essa reconciliação, sendo que no item 31.3 a empresa informa a diferença no tratamento da operação da Sidenor entre as normas, como segue:

Contabilização da Corporación Sidenor: Pelo IFRS, conforme descrito na nota 17.f, a Companhia registra uma participação de $80 \%$ na Corporación Sidenor, correspondente a participação de 40\% adquirida em Janeiro de 2006 mais a participação de 40\% adquirida na mesma data pelo Grupo Santander e para o qual a Companhia tem uma potencial obrigação de adquirir do Grupo Santander. A potencial obrigação de adquirir os $40 \%$ detido pelo Grupo Santander é registrada como um passivo pela estimativa do montante a ser pago no final de cada período de divulgação e é baseado nos termos do contrato com o Grupo Santander.

Pelos US GAAP, a Corporación Sidenor é considerada uma SPE (entidade de propósito específico), pelo qual a Companhia é o beneficiário primário e é consolidado considerando a participação de $40 \%$ adquirida em janeiro de 2006. A obrigação de recompra com o Grupo Santander, dos $40 \%$ do Grupo Santander adquiridos em Janeiro de 2006 é registrado como Participações de minoritários.

Mesmo a participação de $40 \%$ do Grupo Santander ser uma obrigação potencial, por parte da Gerdau, esse valor é classificado como Participações de minoritários. Ou seja, pelo o exposto na nota explicativa, o que justifica-se a contabilização diferenciada deve-se ao fato da Sidenor ser tratada como uma SPE pelas normas norte-americanas.

\section{CONSIDERAÇÕES FINAIS}

Para o alcance do objetivo proposto o estudo abordou o enfoque das três normas contábeis - IFRS, USGAAP e BRGAAP - descrevendo o que caracteriza um título híbrido. Utilizando o exemplo da empresa Gerdau S.A., foi possível verificar diferenças tanto na classificação desse tipo de instrumento financeiro como também em relação a sua evidenciação. 
Ressalta-se que mesmo com classificações distintas entre as três normas a Gerdau divulgou de forma clara, o que possibilita qualquer investidor fazer considerações para seu próprio julgamento. Neste aspecto é que ainda encontram-se as maiores vantagens das normas internacionais e norte-americanas.

Durante a pesquisa foram identificadas outras empresas com operações similares, mas que adotam práticas contábeis diferentes de divulgação; como o caso da Endesa Brasil S.A. (2007). Neste caso há um instrumento entre ela e o International Finance Corporation - IFC, que possui cláusulas de opção de venda das ações adquiridas pelo IFC para a própria Endesa ou para os acionistas. O valor dessa operação foi de $\mathrm{R} \$ 111.025$ mil e foi registrado como Obrigações com o IFC - capital no grupo do Passivo não circulante em contrapartida de Capital social (conta redutora), mesmo elaborando as suas demonstrações conforme as normas brasileiras. Isso indica que deve prevalecer a essência econômica da operação na hora de elaborar as demonstrações contábeis, de forma a retratar o próximo da realidade das operações que envolvem a entidade.

Isso demonstra que, mesmo com o processo de conversão para um padrão único de contabilidade e o acesso em qualquer lugar do mundo das publicações das demonstrações contábeis, as formas de classificação e divulgação ainda divergem em alguns pontos. Esse fato pode ocorrer devido ao grau de exigência dos órgãos regulamentadores e dos stakeholders. Outros fatores, como auditoria externa, também podem influenciar no grau de evidenciação.

Diante do exposto neste trabalho, torna-se importante que o CPC, através de seus pronunciamentos (CPC 14, CPC 38, CPC 39 e CPC 40) ou interpretações, não deixe margem para dupla interpretação e que coloque exigências de divulgação detalhadas e claras, de forma que os usuários possam fazer suas análises considerando o que as empresas contabilizaram, ou não. Deixando margem para dupla interpretação, as empresas, de um modo geral, poderão escolher qual a melhor classificação de acordo com seus interesses, já que alguns índices como endividamento total, perfil de endividamento e liquidez geral são influenciados diretamente por operações de características híbridas.

\section{REFERÊNCIAS}

BARTH, M. E.; LANDSMAN, W. R.; RENDLEMAN Jr, R. J. Option Pricing-Based Bond Value Estimates and a Fundamental Components Approach to Accounting for Corporate Debt, The Accounting Review, v. 73, n. 1, p. 73-102, 1998.

BC - Banco Central do Brasil. Comunicado N. 014.259, de 10 de março de 2006.

BISHOP, Helen; BRADBURY, Michael; ZIJL, Tony V. NZ IAS 32: An Evaluation of the Potential Impact on Financial Reporting by Issuers of Convertible Financial Instruments, Pacific Accounting Review, v. 17, n. 2, December 2005.

BRASIL. Lei $\mathrm{n}^{\circ}$ 6.404, de 15 de dezembro de 1976. Dispõe sobre Sociedade por Ações.

CASSON, Peter. A Re-examination of the Case for Accounting Separately for the Debt and Equity Features of Convertible Debt. Journal of Business Finance \& Accounting, v. 25, Issue 5\&6, p. 595-612, Jun 1998.

CPC - Comitê de Pronunciamentos Contábeis. CPC 14, de 05 de dezembro de 2008.

CVM - Comissão de Valores Mobiliários. Deliberação CVM n 488, de 03 de outubro de 2005. 
CVM - Comissão de Valores Mobiliários. Deliberação CVM n 489, de 03 de outubro de 2005.

CVM - Comissão de Valores Mobiliários. Deliberação CVM n 566, de 16 de dezembro de 2008.

CVM - Comissão de Valores Mobiliários. Instrução 457, de 13 de julho de 2007.

CVM - Comissão de Valores Mobiliários. Instrução Normativa $n^{0} 235$, de 23 de março de 1995.

FASB - Financial Accounting Standards Board. Statement of Financial Accounting Standards No. 150. Accounting for Certain Financial Instruments with Characteristics of both Liabilities and Equity. May 2003.

FIPECAFI - Fundação Instituto de Pesquisas Contábeis, Atuariais e Financeiras. Manual de Contabilidade das Sociedades por Ações: aplicável também às demais sociedades. 7.ed. São Paulo: Atlas, 2007.

GODOY, Arilda Schmidt. Entendendo a Pesquisa Científica. In: HANASHIRO, Darcy Mitiko Mori; TEIXEIRA, Maria Luiza Mendes e ZACCARELLI, Laura Menegon (Orgs.). Gestão do Fator Humano: Uma Visão Baseada em Stakeholders. São Paulo: Saraiva, 2007.

HENDRIKSEN, Eldon S.; BREDA, Michael F. Van. Teoria da contabilidade. Tradução de Antônio Zoratto Sanvicente. Título original: Accounting theory. São Paulo: Atlas, 1999.

IASB - International Accounting Standards Board. International Accounting Standards 32. Financial Instruments: Presentation. Dec. 2003.

RAUPP, Fabiano Maury; BEUREN, Ilse Maria. Metodologia da pesquisa aplicável às ciências sociais. In: BEUREN, Ilse Maria (Coord.) Como elaborar trabalhos monográficos em contabilidade: teoria e prática. São Paulo: Atlas, 2003

SCHMIDT, P.; SANTOS, J. L.; FERNANDES, L. A. Contabilidade Internacional Avançada. 2. ed. São Paulo: Atlas, 2007. v. 1. 464 p

SCHNEIDER, Douglas K.; MCCARTHY, Mark G; HAGLER, J. Larry. Earnings impact of applying international accounting standard 32 to convertible debt: Some evidence for U.S. firms. Journal of International Accounting, Auditing and Taxation, v 6, Issue 1, 1997, p 97-109.

\section{ENDEREÇO DOS AUTORES}

Centro de Ciências Jurídicas e Econômicas Universidade Federal do Rio de Janeiro

Campus da Praia Vermelha

Avenida Pasteur, 250

Rio de Janeiro, RJ - Brasil

22290-240 